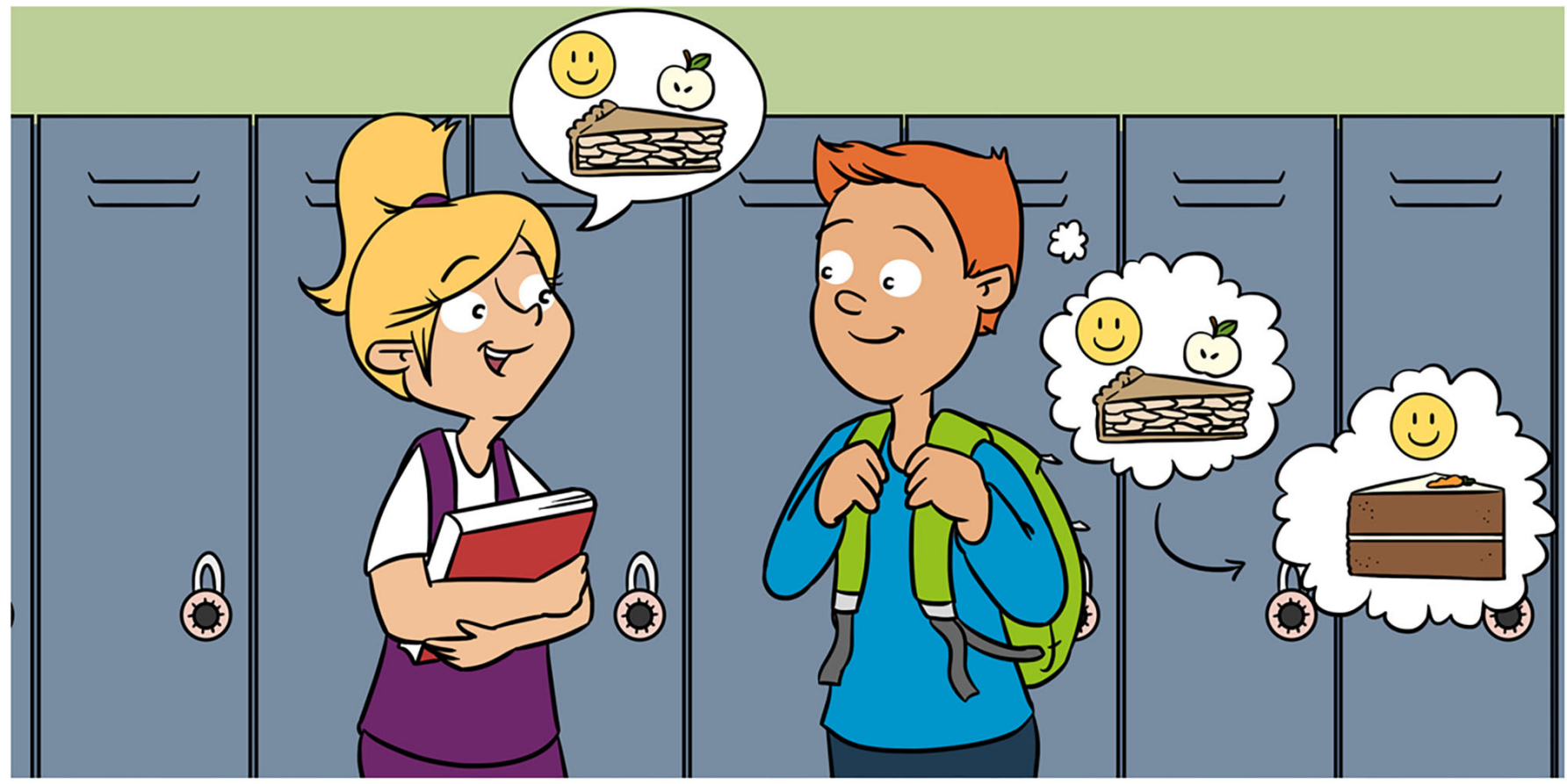

\title{
HOW DO TEENS AND ADULTS LEARN ABOUT OTHER PEOPLE?
}

\section{Christoph W. Korn ${ }^{1,2^{*}}$ and Gabriela Rosenblau ${ }^{3,4^{*}}$}

${ }^{1}$ Institute for Systems Neuroscience, University Medical Center Hamburg-Eppendorf, Hamburg, Germany

${ }^{2}$ Department of General Psychiatry, University of Heidelberg, Heidelberg, Germany

${ }^{3}$ Department of Psychological and Brain Sciences, George Washington University, Washington, DC, United States

${ }^{4}$ Autism and Neurodevelopmental Disorders Institute, George Washington University, Washington, DC, United States

YOUNG REVIEWERS:

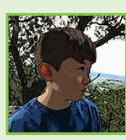

LOUIE

AGE: 12

ORGANIZATION

FOR

HUMAN

BRAIN

MAPPING

AGES: 8-15
Imagine that you meet someone new. You may wonder what they like, for example how much do they like baseball? You then get their feedback, which helps you to predict how much they like something similar, like basketball. We tested how teens and adults decide what others like and dislike and how they learn about others through feedback. This learning process can be described with mathematical models that calculate prediction errors-the difference between how much you think someone likes baseball and their actual preference for it. Teens and adults differed in how quickly they learned about others using this measure. Teens also tended to use a different brain region than adults when learning about the preferences of other people. This study helps us to understand how social learning develops over teenage years. 
Figure 1

The blue persons meets the green person and wonders about how much the green person likes different items. The green person gives feedback for some items.

\section{SOCIAL LEARNING}

A term that summarizes the process of how people learn about, from, or for other people. For example, learning about other people's preferences is a type of social learning

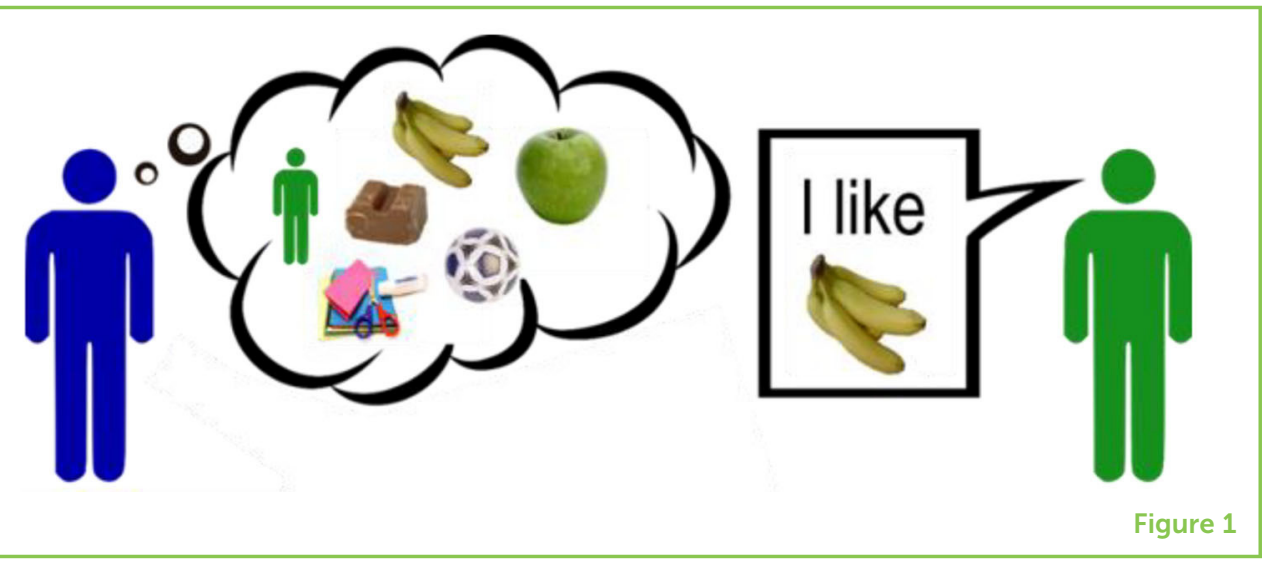

HOW DO YOU LEARN ABOUT OTHER PEOPLE?

You probably often meet new people who are around your age-new students at your school, new members of your sports or music club, new neighbors, and so on. Think back on the last time that you met a new person. At the beginning, you did not know much about them. But, very quickly, you probably got an idea about what the new person likes. How much do they like candy, baseball, or sneakers? Knowing how much a person likes certain objects and activities may help you to predict their preferences for other objects and activities. For example, if they like apple pie, you may think that they also like carrot cake, even though they never told you that they like it. Your predictions about your new peers may affect how you interact with them. If you know that they like baseball, for instance, you might think that they also like basketball and invite them to a basketball game. Your knowledge about other people shapes your relationships with them. For example, a friend may be irritated if you give her a football as a birthday present even though she told you in the past that she does not like rugby and other ball sports. Figure 1 shows an example of how a "blue person" thinks about the preferences of a new "green person" and how this new person gives them feedback.

\section{WHY MIGHT LEARNING DIFFER BETWEEN TEENS AND ADULTS?}

Learning about others is an important type of social learning. Social learning can be helpful, but it can also be tricky. You need to think carefully about the other person's preferences for many different objects and activities. Ideally, over time, you can update your predictions about what a person likes as you get feedback from them. As you grow older, you may become more used to meeting new people because it happens more often. Therefore, teens and adults may differ in how they learn about their peers. In our study, we compared social learning in teens and adults. We looked at brain activity during social interactions when people meet each other $[1,2]$. 
FUNCTIONAL

MAGNETIC

RESONANCE

IMAGING (fMRI)

A way to measure brain activity during a task.

Participants lie in a machine that produces pictures of

brain activity.

\section{PREDICTION}

\section{ERRORS}

The differences between predictions and outcomes or feedback. For example, a prediction error can be the difference between your prediction that somebody likes chocolate a lot and the outcome or feedback that this person does not like chocolate at all.
We used a technique called functional magnetic resonance imaging (fMRI) [3] to test which brain regions contribute to social learning. We expected that the brain regions involved in social learning would differ between teens and adults, because the brain continues to develop during adolescence [4].

\section{WHAT DID THE LEARNING TASK IN OUR STUDY LOOK LIKE?}

We invited 24 teens (between 10 and 17 years of age) and 21 adults (between 23 and 36 years of age) to take part in a study of brain activity using fMRI (Figure 2A) [3]. We designed an experimental task that is similar to getting to know the preferences of a new person in real life. Participants in our study did not directly meet a new person. Instead, they saw a short description of the other person, for example of a student called Mathew (Figure 2B). Participants then saw a picture of an object or activity on the screen, such as an apple. Participants were asked to predict how much Mathew liked apples on a 10-point scale from 1 (not at all) to 10 (very much). After giving their prediction, participants got feedback and saw which rating on the scale Mathew had given for apples. This was repeated for many different objects from three main categories: (1) food items such as fruits, vegetables, sweets, fast foods, and healthy foods; (2) fashion items, such as clothes, shoes, bags, and cosmetics; and (3) activity items, such as toys, gadgets, musical instruments, sports equipment and painting materials. In three sessions, participants learned about three different people like Mathew. Teens learned about other teens and adults learned about other adults. At the end of the experiment, participants rated how much they themselves liked the objects and activities, which allowed us to test if they used their own preferences to predict the preferences of Matthew and the other people (Figure 2C). Participants were also asked to write down their impressions of Mathew and the other people they learned about.

\section{HOW CAN LEARNING ABOUT OTHERS BE MEASURED?}

We can use a calculation to show how good participants were at predicting the preferences of the other people. To do this, we can simply take the difference between participants' predictions and the feedback they got. This difference is called the prediction error. In the example shown in Figure 2B, the participant predicted that Mathew does not like apples very much and would rate them a "4." But the participant received the feedback that Mathew liked apples quite a lot. Mathew chose the rating " 8 ." The prediction error here is 4 , because $8-4=4$. The smaller the prediction error, the better participants are at predicting. We found that prediction errors got smaller over time as participants got more feedback about the person. This learning happened for both teens and adults. But overall, teens had slightly 
Figure 2

Our experimental setup. (A) The participant completed our social learning task while in an $\mathrm{fMRI}$ scanner. (B) While in the scanner, participants saw short descriptions of new people and learned about their preferences for items using a rating task. (C) After the fMRI scan, participants filled out a survey to indicate their own preferences for the same items as presented in the rating task.

\section{MATHEMATICAL}

\section{MODELS}

\section{Mathematical} descriptions of what people do in real life and in experimental studies.

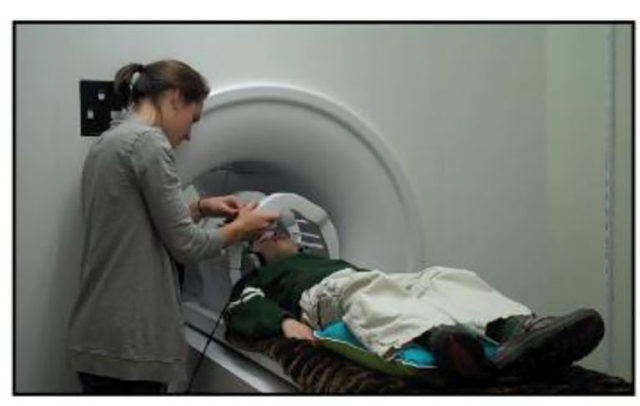

B

A

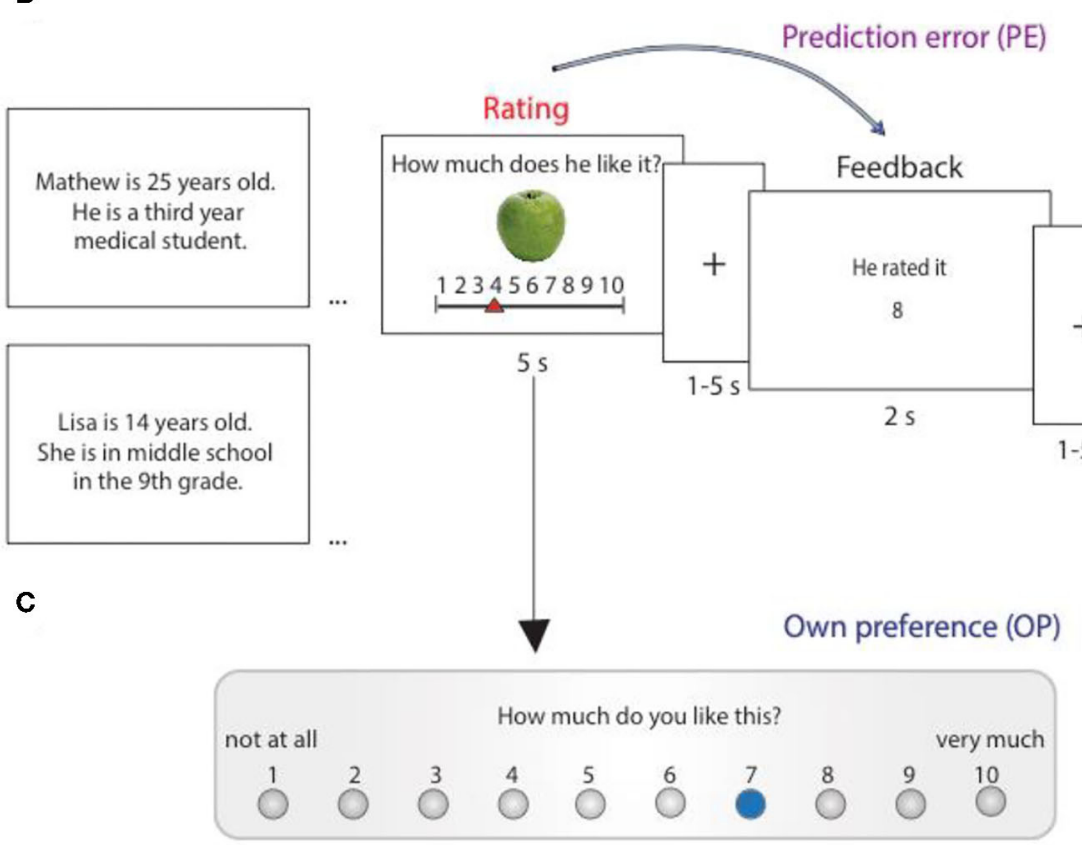

Figure 2

higher prediction errors, which might indicate that teens have less experience with social learning than adults. The written descriptions of the other people that teens and adults gave at the end of the experiment were very detailed, which highlights that both age groups were able to learn about the preferences of their peers in our task.

Many other studies have investigated how humans learn and update their predictions using simple tasks that do not involve learning about other people. These studies have developed detailed mathematical descriptions of the learning process [5]. In our study, we tested whether this type of mathematical models can be extended to our work on social learning about the preferences of other people. We investigated how well different mathematical models captured how participants rated the preferences of others. A good mathematical model should be relatively simple and predict participants' ratings well. 
REINFORCEMENT

\section{LEARNING}

A specific and very powerful type of mathematical model that describes learning based on prediction errors.

\section{MEDIAL}

PREFRONTAL CORTEX (MPFC)

A region in the middle front part of the brain behind the forehead. This large part of the brain is involved in many processes, such as learning, making decisions, and thinking about others.

\section{WHICH MATHEMATICAL MODELS DESCRIBE LEARNING ABOUT OTHERS?}

Our three main models made different assumptions about how people rate the preferences of others. The first model was that participants do not learn at all. When you meet a new person, you could just think that this person likes exactly what you like. This may be smart in the beginning but over time you should learn how the other person differs from you.

Our second main model is a commonly used learning model, called the reinforcement learning model. This model has been used often to describe learning in both animals and humans [5]. Based on this model, participants learn about their surroundings through feedback. Let us say that participants are presented with two pictures, one is more and one less likely to give participants a reward. If participants choose one of the two pictures and then get a reward, they learn that it is better to pick that picture in the future. The way they learn is by updating their prediction error: the difference between their prediction that the picture gives a reward and the outcome. This prediction error will influence which picture participants choose in the future.

Our third main model combined the two models described above. This combination model was best at describing participants' ratings, both for teens and for adults. Teens were slower than adults at updating their predictions. Slower updating is not necessarily bad. Updating too quickly has the danger that recent feedback is weighted too much. As an example, if you think your friend likes all chocolate bars and you then learn that she dislikes chocolate bars with peanuts, you should not use her response for peanut chocolate bars too quickly to update your prediction of how much she likes chocolate bars in general. Overall, the prediction updating speed was related to how old the teens were, which further suggests that learning changes with age.

\section{WHICH BRAIN REGIONS HELP US LEARN ABOUT OTHERS?}

We linked the mathematical models to participants' fMRI data [3]. By doing this, we could see which brain regions were related to participants' predictions of the other persons' preferences and to predictions errors. A brain region is related to the processing of these numbers if its activity scales with these numbers. That is, such a region shows higher activity during time points with higher prediction errors and lower activity during time points with smaller prediction errors.

We expected activity in the medial prefrontal cortex (MPFC), a region in the middle front part of the brain behind the forehead, to be involved 
Figure 3

Teens and adults seem to use different brain regions to learn about the preferences of others. (A) In adults, activity in the medial prefrontal cortex (MPFC) relates to their ratings of what another kid might like. (B) Teens more often use a brain area called the fusiform gyrus, a region in the back of the brain. The numbers on the $y$-axis are in arbitrary units (a.u.), which means that the exact magnitudes cannot be interpreted directly.

\section{FUSIFORM GYRUS}

A region in the a region in the back of the brain, which has been linked to learning and to perceiving and recognizing different types of stimuli, such as different faces.

1 If you want to read more about the neural bases of social learning about and from other people, check out this paper [6].

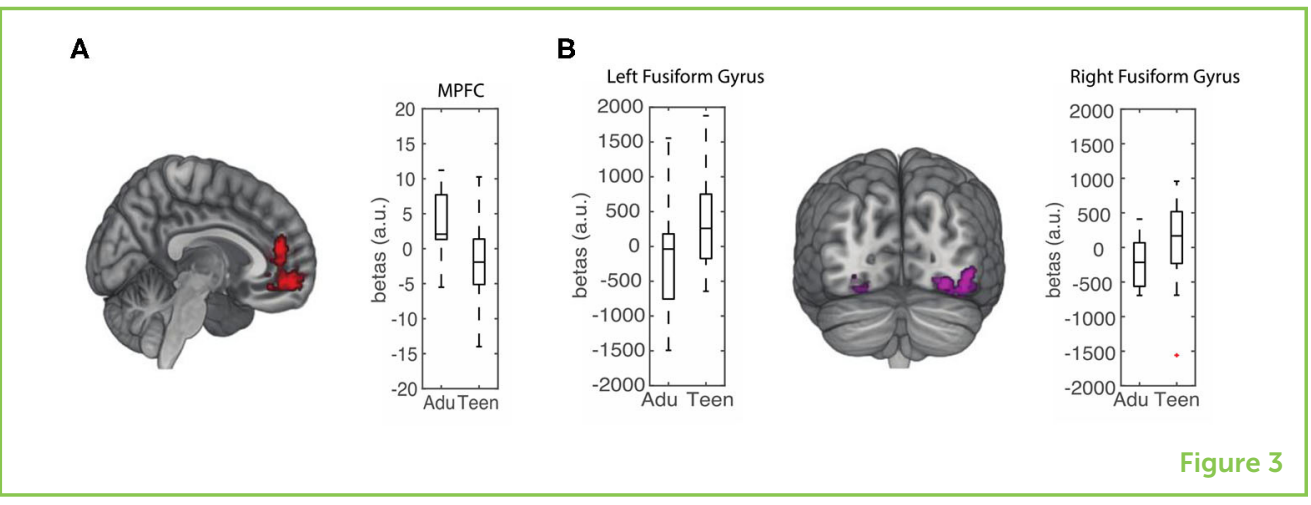

in thinking about the preferences of others. This brain region has been linked to complex learning processes and to social thought processes, such as thinking about oneself and about other people [1, 2]. The MPFC also undergoes a lot of developmental change during adolescence [4], which is not the case for many other brain regions that develop earlier. Indeed, we found that activity in the MPFC reflected the predictions of adults and less so of teens (Figure 3). In contrast, another brain region, called the fusiform gyrus, which is in the back of the brain, was related to prediction errors in teens but not in adults. This suggests a developmental shift in the brain regions that are involved in social learning.

\section{FUTURE QUESTIONS}

There are many things to learn about other people. For example, what would they do in various situations? Would they share with you or keep everything for themselves? It would be interesting to know if learning about such activities is similar to learning about preferences ${ }^{1}$. Additionally, some people have difficulties understanding what others think or feel. For example, autistic teens might show differences in social learning. If so, it would be interesting to know if different brain regions are involved in the social learning of kids with autism and if training can help them.

Our study shows how mathematical models and brain activity can describe differences in how teens and adults learn about other people. This is important for understanding how teens develop.

\section{ACKNOWLEDGMENTS}

We would like to thank Athina Tzovara and Julia Kam for organizing the live review for kids at OHBM. 


\section{ORIGINAL SOURCE ARTICLE}

Rosenblau, G., Korn, C. W., and Pelphrey, K. A. 2018. A computational account of optimizing social predictions reveals that adolescents are conservative learners in social contexts. J. Neurosci. 38:974-88. doi: 10.1523/JNEUROSCI.1044-17.2017

\section{REFERENCES}

1. Ruff, C. C., and Fehr, E. 2014. The neurobiology of rewards and values in social decision making. Nat. Rev. Neurosci. 15:549-62. doi: 10.1038/nrn3776

2. Yang, D. Y., Rosenblau, G., Keifer, C., and Pelphrey, K. A. 2015. An integrative neural model of social perception, action observation, and theory of mind. Neurosci. Biobehav. Rev. 51:263-75. doi: 10.1016/j.neubiorev.2015.01.020

3. Hoyos, P. M., Kim, N. Y., and Kastner, S. 2019. How is magnetic resonance imaging used to learn about the brain? Front. Young Minds 7:86. doi: $10.3389 /$ frym.2019.00086

4. Mills, K., Goddings, A., and Blakemore, S. 2014. Drama in the teenage brain. Front. Young Minds 2:16. doi: 10.3389/frym.2014.00016

5. Niv, Y., and Langdon, A. 2016. Reinforcement learning with Marr. Curr. Opin. Behav. Sci. 11:67-73. doi: 10.1016/j.cobeha.2016.04.005

6. Koele, I., Westhoff, B., and van de Groep, I. 2020. Social learning and the brain: how do we learn from and about other people? Front. Young Minds 8:95. doi: 10.3389/frym.2020.00095

SUBMITTED: 17 May 2020; ACCEPTED: 08 December 2020; PUBLISHED ONLINE: 18 December 2020.

EDITED BY: Julia W. Y. Kam, University of Calgary, Canada

CITATION: Korn CW and Rosenblau G (2020) How Do Teens and Adults Learn About Other People? Front. Young Minds 8:563084. doi: 10.3389/frym.2020.563084

CONFLICT OF INTEREST: The authors declare that the research was conducted in the absence of any commercial or financial relationships that could be construed as a potential conflict of interest.

COPYRIGHT @ 2020 Korn and Rosenblau. This is an open-access article distributed under the terms of the Creative Commons Attribution License (CC BY). The use, distribution or reproduction in other forums is permitted, provided the original author(s) and the copyright owner(s) are credited and that the original publication in this journal is cited, in accordance with accepted academic practice. No use, distribution or reproduction is permitted which does not comply with these terms. 

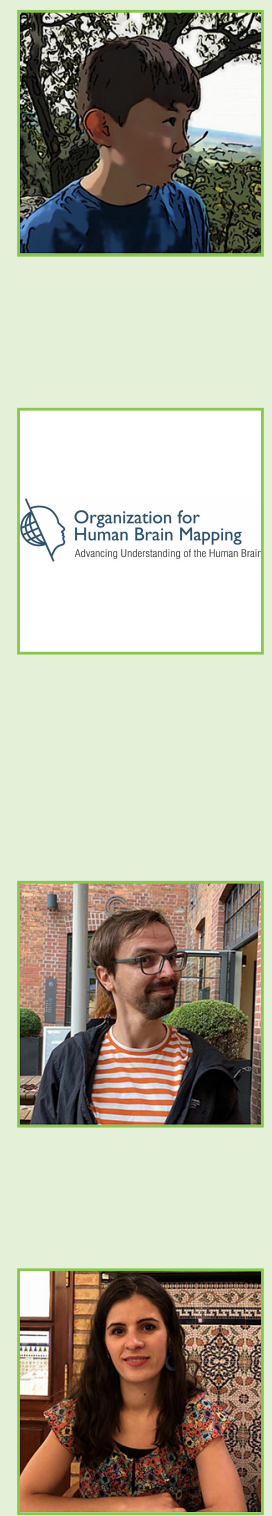

\section{YOUNG REVIEWERS}

\section{LOUIE, AGE: 12}

Louie is a precocious sixth grader in Washington, DC. His interests include studying ancient civilizations, math, and of course, all topics in science. He gained early exposure to neuroscience by frequently accompanying his parents to their labs and talking with graduate students and post-docs. In his free time, he is learning to build simple circuits. He also loves playing violin, bike riding, and reliably beating his father in chess.

\section{ORGANIZATION FOR HUMAN BRAIN MAPPING, AGES: 8-15}

As part of the Kids Live Review Event at OHBM 2020, Adrian, Louie, Pinaki, Reina, and Tian, grilled the scientists on their work in front of an audience. This group of elite reviewers provided pointed feedback that improved the quality of each of these papers, ranging from boredom, irritability and social learning, to brain surgeries and Alzheimer's disease.

\section{AUTHORS}

\section{CHRISTOPH W. KORN}

I am a cognitive neuroscientist. I am interested in how humans learn and make decisions in social interactions. For $m e$, it is fascinating how the human brain enables learning and decision-making. Therefore, I use behavioral experiments, brain imaging, and computational techniques. I have recently moved from the University Medical Center Hamburg-Eppendorf to the University of Heidelberg. *christoph.kornamed.uni-heidelberg.de

\section{GABRIELA ROSENBLAU}

I am a developmental cognitive neuroscientist. I am studying how social decision making develops in childhood and adolescence as our brains mature. An important goal of my research is to understand changes in social development of people with developmental disorders, for example autism. I work at George Washington University in Washington, DC, USA. *grosenblau@gwu.edu 